\title{
THOMAS CORNEILLE, Théâtre complet
}

\section{Monica Pavesio}

\section{OpenEdition \\ Journals}

\section{Edizione digitale}

URL: http://journals.openedition.org/studifrancesi/15257

DOI: 10.4000/studifrancesi. 15257

ISSN: 2421-5856

\section{Editore}

Rosenberg \& Sellier

\section{Edizione cartacea}

Data di pubblicazione: 1 décembre 2018

Paginazione: 489-490

ISSN: 0039-2944

\section{Notizia bibliografica digitale}

Monica Pavesio, «thomas conneille, Théâtre complet», Studi Francesi [Online], 186 (LXII | III) | 2018, online dal 01 janvier 2019, consultato il 06 janvier 2021. URL: http://journals.openedition.org/studifrancesi/ 15257 ; DOI: https://doi.org/10.4000/studifrancesi. 15257

Questo documento è stato generato automaticamente il 6 janvier 2021.

\section{(c) (†)}

Studi Francesi è distribuita con Licenza Creative Commons Attribuzione - Non commerciale - Non opere derivate 4.0 Internazionale. 


\title{
THOMAS CORNEILLE, Théâtre complet
}

\author{
Monica Pavesio
}

\section{NOTIZIA}

THOMAS CORNEILLE, Théâtre complet, tome I, Paris, Classiques Garnier, 2015, 842 pp.

1 Grazie al rinnovato interesse per le opere di Thomas Corneille generato dagli studi di Le Chavalier (G. LE CHEVALIER, La Conquête des publics. Thomas Corneille, homme de théâtre, Paris, Classiques Garnier, 2012, recensione di M. Pavesio in SF 173, 2014, p. 359) e all'attenzione della collana «Bibliothèque du Théâtre français» diretta da Charles Mazouer per i drammaturghi secenteschi, esce per le edizioni Garnier il primo volume delle opere del più giovane dei fratelli Corneille.

Il volume del Théâtre complet di Thomas Corneille, diretto da Christopher Gossip, contiene le edizioni delle sue prime pièces, ossia Les Engagements du hasard e Le Feint Astrologue, edite da L. Picciola, Don Bertrand de Cigarall, curata da C. Dumas e L'Amour à la mode annotata e presentata da M. Serrano Mañes.

Un'introduzione generale illustra la carriera, la ricezione delle opere del drammaturgo e le norme editoriali. Vengono utilizzate le prime edizioni delle opere, con la segnalazione delle varianti presenti nelle edizioni successive. Le edizioni delle singole pièces, tutte appartenenti al primo periodo della produzione teatrale di Thomas Corneille, fortemente segnata dall'influenza spagnola, sono precedute da un'introduzione, dai principi d'edizione e da una bibliografia. Un glossario, una bibliografia generale e un indice dei nomi concludono il volume. 